\title{
FRONTEIRAS INTERCULTURAIS NA IBEROAMÉRICA: O EXEMPLO DOS POVOS INDÍGENAS NO BRASIL
}

\author{
Alzira Lobo de Arruda Campos ${ }^{1}$ \\ Marília Gomes Ghizzi Godoy ${ }^{2}$ \\ Patrícia Margarida Farias Coelho ${ }^{3}$
}

\begin{abstract}
Resumo: Da chegada dos europeus à América aos tempos atuais, a identidade iberoamericana apresenta-se como o resultado de migrações multisseculares e sucessivas de homens, plantas e animais entre o Velho e o Novo Mundo, criando e destruindo fronteiras identitárias entre o "civilizado" e o "selvagem". As fronteiras transmitem um aprendizado recíproco sobre confluências e oposições interétnicas, operado num campo extremo de desigualdade entre dominantes europeus e dominados ameríndios. Esse acontecimento, de dimensão planetária, é visto a partir das fronteiras culturais entre o universo mágico indígena e o ocidental, resultando num processo de aniquilamento, resiliência e adaptação da identidade pluriétnica e multidimensional iberoamericana, que toma, por referência central, os povos indígenas históricos e atuais - da nação brasileira.
\end{abstract}

Palavras-chave: Fronteiras culturais. Interculturalidade. Racismo e desigualdade. Adaptação e resistência ameríndia. Indígenas do Brasil

\section{INTERCULTURAL FRONTIERS IN IBEROAMERICA: THE EXAMPLE OF INDIGENOUS PEOPLES IN BRAZIL}

\begin{abstract}
From the arrival of Europeans to America to the present times, Ibero-American identity is presented as the result of multisecular and successive migrations of men, plants and animals between the Old and the New World, creating and destroying identity boundaries between the "civilized" and the "savage". The borders convey a reciprocal learning about interethnic confluences and oppositions, operated in an extreme field of inequality between European and Amerindian-dominated dominants. This event, of a planetary dimension, is seen from the cultural boundaries between the indigenous and western magic universe, resulting in a process of annihilation, resilience and adaptation of ibero-American pluriethnic and multidimensional identity, which takes, by central reference, the indigenous peoples - historical and current - of the Brazilian nation.
\end{abstract}

Keywords: Cultural boundaries; interculturality; racism and inequality; amerindian adaptation and resistance; indigenous peoples of Brazil.

\footnotetext{
${ }^{1}$ Mestra e Doutora em História Social (USP/SP); Livre-docente em Metodologia da História (UNESP/FRANCA); Docente do Programa de Mestrado em Ciências Humanas (UNISA/SP).

${ }^{2}$ Mestra em Antropologia Social (USP/SP); Doutora em Psicologia Social (PUC-SP); Docente do Programa de Mestrado em Ciências Humanas (UNISA/SP). Integrante do GEMI (Grupo de Estudos Migrações e Identidade CERU/USP).

${ }^{3}$ Mestra em Letras pela Universidade Presbiteriana Mackenzie; Doutora em Comunicação e Semiótica pela Pontifícia Universidade Católica de São Paulo; Docente do Programa de Mestrado e Doutorado em Educação da Universidade Metodista de São Paulo; Docente e Coordenadora do Programa de Mestrado em Ciências Humanas (UNISA/SP).
} 


\section{Introdução}

A etnoidentidade dos ameríndios apresenta-se como um epifenômeno da colonização da América pelas Coroas Ibéricas, que implicou a desculturação violenta de milhões de indivíduos, fragmentando as suas identidades, sob a bandeira da "civilização". Nos dias atuais, em que a marcha triunfante do capitalismo financeiro substituiu o conceito humanista do homem, reificando as relações sociais na esfera de produção, os direitos indígenas transformaram-se num dos temas principais do debate sobre a diversidade cultural, figurando como contraponto a políticas globais que lutam por uma identidade única - o consumidor compulsivo de produtos e de técnicas dominados pelos centros do capitalismo internacional. Nessa linha, a sobrevivência de culturas alternativas, que rejeitem os mitos do individualismo e da busca desenfreada de lucros, aparece como um elemento de interesse para a humanidade como um todo.

No amplo painel da organização estrutural dos povos, o nomadismo e a transumância nomeiam os deslocamentos regulares de homens e rebanhos, que constituem um dos traços mais marcantes da humanidade. O nomadismo, ao contrário da transumância, arrasta tudo consigo (pessoas, animais e mesmo as casas) ao longo de enormes percursos. Desde que podemos acompanhar a história desse movimento, vemos populações inteiras, tangidas pelo flagelo da fome, deslocando-se do Leste para Oeste, ao contrário do eixo de rotação da Terra. A muralha da China materializa esse fenômeno, uma vez que foi construída com o intuito de proteger o império da investida das hordas nômades das estepes asiáticas. As mesmas hordas que, tangidas pela seca prolongada dos Séculos III e IV D.C., provocaram as invasões bárbaras que destruíram a hegemonia romana sobre o mundo mediterrânico, dando origem à Idade Média, às “trevas dos mil anos”. De certo modo, os piratas e corsários da Modernidade podem ser vistos como a continuação desse fenômeno multissecular, que se transfigura, na atualidade, no espetáculo dramático de levas de emigrantes que tentam fugir da miséria de seus países de origem, galgando as fronteiras de nações desenvolvidas, afogando-se no mar ou sendo aprisionados em acampamentos. Os grupos menores, que triunfam nesse objetivo, sujeitam-se a trabalhos rejeitados pelos nacionais, e têm as suas identidades estilhaçadas pelos estigmas dos "filhos de Caim" contemporâneos. A discriminação desses "invasores" é marcada por uma ideologia arcaica, que mal disfarça a discriminação racista clássica, aliás, assumida por movimentos neonazistas atuais, em sua inteireza. É interessante notar que a migração de 
homens e ideias acompanha o trajeto do capitalismo, cujo coração nomadizou do Norte da Itália e Sul da Alemanha aos Países Baixos, e, desses, para a Inglaterra, atraído pela Revolução Industrial do século XVIII. Em continuidade a sua caminhada, o coração do capitalismo deslocou-se, em finais do século XIX, para os Estados Unidos, bifurcando-se entre Wall Street e o Vale do Silício. Nos dias atuais, existe a perspectiva de que essa marcha se encaminhe para o Pacífico, atraído pela pujança econômica da China e do Japão.

O processo, acima esquematizado, transcorre em um cenário de extrema competitividade, demarcada pela concentração de lucros em mãos de vencedores, da socialização de prejuízos para os perdedores. Os primeiros formados, no presente e no passado, por uma parcela ínfima da população mundial; os segundos, por mais de $90 \%$ da humanidade. A extensão planetária desse processo, conhecido atualmente por mundialização/globalização, é visto no viés da conquista e da colonização do Novo Mundo pelos burgueses conquistadores ibéricos, com as consequências inevitáveis acarretadas para a identidade dos povos e países latino-americanos.

\section{Metodologia}

Nos processos migratórios no cenário das culturas racializadas e fronteiras de identidade, esta reflexão distingue o exemplo dos indígenas no Brasil, tomado como um método individualizante do conceito geral de raça e identidade, que permite penetrar no sentido profundo dos acontecimentos. Sob a roupagem histórica da colonização lusitana, teorias e tipos se restringem ao problema eterno do conceito, caminhando das dimensões generalizantes de seus significados para “abstrações intuitivas”, isto é, aos conceitos sublunares (VEYNE, 1983, p. 149-150).

A explicação do mundo atual coloca problemas complexos, na medida em que se revela em termos sempre obscuros, solicitando luzes múltiplas de disciplinas variadas: história, geografia, demografia, economia, antropologia, psicologia, filosofia, além das ciências biológicas, físico-naturais e exatas. A chave, entretanto, permanece no campo da história, uma vez que os dias em que estamos se explicam, em parte, pelos dias que os precederam e que se prolongam em nossas vidas por inumeráveis consequências. A aceleração da globalização, a partir de 1960, provocou consequências políticas e culturais profundas ao assumir a forma de um mercado global hegemônico e sem controles. Em primeiro lugar, acentuou dramaticamente as desigualdades entre os homens e as nações, criando importantes tensões sociais e políticas, diante da impossibilidade prática de vastas populações, em especial no mundo 
subdesenvolvido, de aceder aos benefícios prometidos pelo neoliberalismo imperante. A tecnologia tem um enorme poder na contemporaneidade, provocando uma revolução constante na economia e na política, em escala global, pois o imperialismo de hoje apoia-se necessariamente em seu domínio sobre a tecnologia.

Globalização e mundialização, referindo-se, respectivamente, à homogeneidade das estruturas espirituais e materiais da humanidade, constituem conceitos recorrentes nos modelos analíticos atuais, mas ambos os termos devem ser submetidos a uma reflexão profunda sobre os significados que assumem abaixo ou acima da linha do Equador. É o exercício que faz Gruzinski (2014, p. 22), ao pensar sobre a mundialização "a partir de uma terra que não seria nem a Europa nem os Estados Unidos, uma periferia que se tem ainda como um inesgotável reservatório de exotismos e de primitivismos". A respeito dos laços entre a mundialização e o amálgama generalizado dos homens e das sociedades sobre o planeta e do local em que se deteriam as mestiçagens, Gruzinski (2014) mostra a impossibilidade de fazer com que entrassem na mundialização as multidões de grupos excluídos, como se houvesse várias maneiras de nela se entrar, porque, em toda a parte do planeta, misturas se chocam contra barreiras e contra modelos de vida originários do Ocidente. Mundialização e mestiçagens relacionam-se de forma ambígua e repousam em "estruturas gigantescas e enigmáticas de uma história que se define, há muito tempo, como planetária”.

É preciso fazer um esforço analítico para que se pense sobre o que está em jogo nesses conceitos para os moradores das periferias do capitalismo mundial, em sua imensa diversidade etnocultural, e na resistência que oferecem para assumir a identidade única proposta pela tecnologia global. Na medida em que as sociedades se organizam, os homens se interessam em construir linhas divisórias, demarcando territórios e possessões, cujas fronteiras operam como mecanismos de autodefinição e autolimitação, favorecendo atores individuais, mas restringindo o seu significado.

A obra clássica Grupos Étnicos e suas Fronteiras abre a possibilidade para que se entenda a identidade como um processo oriundo da ordem de relações estabelecidas entre os grupos sociais, com o objetivo de organizar suas trocas (BARTH, 1998, p. 125-126). Logo, a definição de uma cultura particular "resulta unicamente das interações entre os grupos e os procedimentos de diferenciação que eles utilizam em suas relações" (CUCHE, 2002, p. 182). A aderência ao grupo étnico é a primeira e a mais fundamental das vinculações sociais, pois é ela que estabelece os laços determinantes baseados em uma genealogia comum, pelo fato de ser no grupo étnico que os sentimentos e as relações se apresentam de modo mais estruturante e mais forte. A partir dessa afirmação, entende-se a identidade cultural como uma propriedade 
essencial para o grupo "porque é transmitida por ele e no seu interior, sem referências aos outros grupos. A identificação é automática, pois tudo está definido desde seu começo" (CUCHE, 2002, p. 180). Nessa linha, vários autores ressaltam que conceituar a etnicidade não implica estabelecer um modelo de pluralismo étnico como fundamento da organização social e política dos grupos em geral, mas sim analisar as formas pelas quais uma determinada visão de mundo apresenta-se pertinente para os seus atores (POUTIGNAT; STREIFF-FENART, 1998, p. 16).

Desse prisma, é preciso observar que as fronteiras fechadas bloqueiam toda evolução e produzem processos de involução destinados ao esgotamento. Não obstante, as fronteiras são inevitáveis e necessárias, pois exercem a tarefa de preservação identitária e de valores culturais, significando uma superfície de fricção, que mantém vigente a consciência coletiva. A diversidade cria fronteiras, tanto como as fronteiras são fontes de diversidade. As fronteiras, assim como as sociedades, não são estáticas: elas se reformulam e mudam constantemente. A fronteira, em todas as discussões encetadas sobre a natureza unilinear ou pluralista das disciplinas, surge como conceito chave ao definir zonas de controle, no mundo e na academia. As fronteiras reapresentam o conceito do "entre lugar" que há mais de 40 anos tem servido como ferramenta de trabalho reativada pela noção de diferença, a revelar a singularidade dos latino-americanos, rejeitada pela escola autocrática das metrópoles - reais ou presumidas. Trata-se de um "espaço entre" no qual os modelos tradicionais são postos em questão pela presença altissonante dos grupos situados nos porões sociais, explicados por núcleos tradicionais de poder, presentes nas universidades e na sociedade envolvente. $O$ espaço ideológico, físico, humano e intelectual, decorrente desse novo "entre lugar", tem sido ocupado por afros e indígenas, que já dispõem de universidades próprias, de grupos de trabalho e de políticas públicas específicos, trazendo inovações das mais importantes para o estudo da sociedade brasileira, a preponderante das quais se refere a uma história contada pelos próprios atores, sem a intermediação do "outro". Nessa área, o brasileiro passou a ser analisado, não apenas em suas raízes estruturais (índias, portuguesas e africanas), mas em sua identidade subcontinental: a latino-americana.

A "antropologia das margens" oferece uma perspectiva preciosa para o estudo de identidades amplas e ainda insuficientemente conhecidas. Em princípio, esse campo de investigação inclui as identidades culturais mestiças, formadas de um lado e do outro do Atlântico, em consequência da conquista e colonização da América pela empresa mercantilista europeia.

Pesquisadores contemporâneos entendem que a etnoidentidade deva ser inserida em modelos analíticos estruturais, avaliando que se trata de uma linguagem que informa a respeito 
de grupos sociais, por meio da utilização de signos que obedecem à lógica interna das culturas específicas de cada agrupamento humano. Vistas como sistemas, as culturas apresentam as suas partes interdependentes e passam a ser utilizadas como signos em um conjunto multiétnico, tornando-se parcelas de um metassistema que as organiza, conferindo-lhes, ao mesmo tempo, novas posições e significados. A mudança do sistema de referência acaba por provocar uma transformação do significado dos itens culturais, e o traço cultural se altera, embora sob a aparência de continuar o mesmo, tornando-se, no mínimo, bissêmico, na medida em que um primeiro sentido prende-se ao sistema interno e um segundo ao sistema externo (CUNHA, 2012, p. 121-122).

A diversidade das abordagens da realidade brasileira, especialmente em sua bioeconomia, indica que estudos que focalizem temáticas africanas e indígenas são fundamentais para que a compreensão histórico-social se estenda, acolhendo novas versões que possam se opor ao modelo da utopia/distopia global. A questão referente à garantia de sobrevivência de sociedades alternativas na sociedade mundializada e globalizada de nossos dias é respondida por Descola (2016, p. 50) quando declara que esses processos não significam, necessariamente, uma uniformização dos modos de vida. Essa uniformização, no caso de acontecer, provocaria reações de defesa que viriam a realçar o caráter distintivo que cada sociedade ou grupo considera ser a marca de sua identidade. Processo semelhante implicaria um duplo movimento: primeiramente, uma tendência à unificação tanto das técnicas como das maneiras de pensar, o que provocaria movimentos de reação ou de defesa, cujos resultados acabariam por realçar as diferenças. Não é preciso, segundo Descola (2016), ver a mundialização como uma ocidentalização generalizada: as culturas sobreviveriam a esse processo, embora aderindo a alguns de seus aspectos materiais.

\section{A colonização europeia da América}

No amplo painel da colonização na América, a etnoidentidade é avaliada como um epifenômeno da história da desculturação violenta à qual os ameríndios foram submetidos e de sua luta por direitos, como um dos temas mais amplos do debate sobre a diversidade cultural e a pluralidade étnica, figurando como um contraponto de políticas nacionais globalizantes, que se opõem à sobrevivência de culturas alternativas.

Tornada realidade a colonização, iniciou-se o processo desintegrador das culturas ameríndias, com o estabelecimento definitivo do modelo de exploração, que resultou em conflitos inevitáveis entre os invasores ádvenas e os habitantes autóctones. 
Aos conceitos sobre identidade, torna-se essencial adicionar os processos históricos ligados à colonização ibérica, a fim de entender que as interações entre grupos e procedimentos diferenciais passaram a contar, do século XVI aos nossos dias, com os fatos históricos relacionados a um grupo estranho, dotado de grandes poderes de dominação sobre o "gentio" ou os "negros da terra" - hoje, os indígenas a "assimilar".

A história indígena no mundo colonial ibérico enfrenta o problema metodológico de constituir, em geral, uma das versões do europocentrismo clássico que marcou a historiografia tradicional. Por essa historiografia, os primitivos habitantes da terra ocupariam um lugar secundário e interpretado de acordo com a óptica dos colonizadores. Nessa vertente, é preciso notar que o "presente etnográfico" ancora-se no passado histórico, vindo a colocar um assunto que tem preocupado os investigadores: as relações possíveis entre os elementos materiais e imateriais trazidos pelos colonizadores e aqueles pertencentes aos silvícolas e aos milhões de africanos desembarcados na América como escravos. No viés dos evolucionistas do século XIX, as culturas dos dominados seriam a razão de nosso atraso. A dualidade entre a cultura ameríndia e a europeia apresenta-se desde os primeiros trabalhos científicos. A etnologia, por exemplo, utiliza-se de um modelo analítico que define um determinado estado tradicional das sociedades (por vezes, abusivamente citadas no singular), como estático, temporalmente sincretista e homogêneo, próprio a figurar em arquivos ou museus culturais e a ser submetido a um método comparativista (MONIOT, 1974, p. 107).

O panorama do processo adaptativo das populações ameríndias aos invasores europeus apresenta uma movimentação característica condicionada na ideia de fronteiras estabelecidas entre paisagens, populações, hábitos, instituições, técnicas e idiomas que aqui se defrontavam e por vezes se apagavam, deixando espaço para o aparecimento de elementos mistos ou simbióticos, e, em outras circunstâncias, se afirmavam, pelo menos provisoriamente, até serem vencidas por produtos que surgissem de modo mais ativo, mais fortes ou melhor equipados (HOLANDA, 1957, p. V-VI).

Tulio Halperin Donghi (1972, p. 39), ao estudar a etnicidade na América hispânica, considera que, desde Montevidéu, uma capital moderna e aberta aos ventos universais, na qual um funcionário não conseguia, mesmo apoiado numa declaração judicial sobre a pureza de seu sangue espanhol, esquivar-se de uma campanha insistente que o definia como mestiço, e portanto indigno de ocupar cargos de confiança, até a Venezuela, cuja nobreza crioula se fazia porta-voz de resistências maiores contra a largueza com que as autoridades régias distribuíam atestados de fidalguia àqueles que os pudessem pagar, a mestiçagem biológica esmorece diante de critérios econômicos e sociais hierarquicamente superiores, levando o autor citado a estender 
para a paisagem mais ampla da América Latina o conceito de "raça social", empregado inicialmente por um pensador peruano para os índios.

Nos combates travados para a conservação de sua identidade, os povos indígenas afirmam-se em sua própria história, contribuindo para o avanço do conhecimento dos cultural studies das principais universidades, em sua grande maioria oriundos do espaço pós-colonial francófono, hispanófono ou lusófono.

Os ameríndios vivem em nossos dias uma das aventuras mais decisivas de sua história: eles se encontram engolfados no turbilhão das transformações técnicas, econômicas, culturais, de um mundo pela primeira vez unificado e dominado pelas grandes potências industriais que têm em mão o destino da humanidade. Ora, a sociedade indígena permaneceu, durante séculos, à parte das transformações que conduziram as sociedades hoje "desenvolvidas" a aceder a sua situação atual. O problema de sua adaptação às condições modernas de existência se coloca então para ela sob o aspecto de uma reação a um choque brutal, a um impacto que a atinge em seus fundamentos culturais mais profundos e contra o qual ela se encontra em parte desarmada, constrangida a se transformar. A cultura tradicional indígena não pode sonhar em se "desenvolver" sobre o modelo vivido e concebido pelas sociedades industriais. As dificuldades de adaptação à "nova ordem" prendem-se à vitalidade de uma cultura que muitos observadores consideravam que iria se destruir com o tempo e cujas resistências surpreendem os especialistas "ocidentais", diante da persistência de estruturas e de práticas que eles consideravam como incompatíveis com uma perspectiva de "desenvolvimento", porque as viam como "arcaicas" ou "primitivas". Desse ângulo, as políticas de Estado portuguesas e castelhanas assumiram a tendência de dar a seus planos de desenvolvimento a forma de uma luta contra "o costume", de procurar fazer tabula rasa de tudo o que relembrasse o passado, transformando a tradição em tabu nos meios econômicos e políticos.

No enfrentamento desse desafio, compete ao pesquisador incluir métodos da microssociologia que permitem substituir o interrogatório dos informantes pela observação pessoal dos atores sociais, decifrando os seus dramas individuais e coletivos (MONIOT, 1974, p. 118-120).

A versão da história, adequada à percepção que os indígenas têm sobre a sua identidade, ancora-se em um passado povoado por equívocos e preconceitos sobre a razão indígena, originados abusivamente por indivíduos alógenos à população que habitava a América, em tempos anteriores à chegada dos burgueses conquistadores. As estatísticas são, obviamente, estimativas, mas é provável que a população da América pré-colombiana equivalesse à da Europa, da mesma época. Não podemos fornecer números exatos, mas as aproximações são 
possíveis e aceitáveis para a Itália e Portugal, pouco arriscadas no que toca à França e à Espanha. Do lado ocidental, no final do século XVI, haveria um total de 38.000 .000 de habitantes: 8.000.000 em Espanha; 1.000.000 em Portugal; 16.000.000 em França; 13.000.000 em Itália (BRAUDEL, 1983, p. 441).

Os totais acima foram multiplicados com o expansionismo europeu na América, em razão destacada da introdução do milho e da batata, as bases da alimentação nos Impérios Asteca e Inca, na alimentação dos europeus, especialmente nas camadas mais pobres da população, que puderam, pela primeira vez, "encher a barriga", com produtos desprezados pelas elites. Ainda mais, como tanto o milho como a batata são plantas forragíferas, os rebanhos de animais de pequeno e médio porte (galinhas, patos, gansos, ovelhas, porcos, cabras) cresceram e permitiram que os vilões se alimentassem de carne, uma vez que a caça lhes era proibida, sendo um apanágio dos nobres e burgueses. Por conseguinte, a revolução agrária que se operou na agricultura europeia, no século XVII, foi uma das consequências mais importantes da introdução do milho e da batata na dieta alimentar da população. Um século depois, essa revolução ocasionou a primeira revolução demográfica da história, ao equilibrar o crescimento populacional com o crescimento dos meios de subsistência. O primeiro crescimento, segundo Malthus, obedecia a uma proporção geométrica, enquanto que, para o segundo, a proporção era aritmética. Além de alimentada, a população deveria ser vestida. Assim, não por acaso, a Revolução Industrial se deu, especialmente, no ramo da tecelagem. Mas, das infraestruturas, as mudanças ascenderam às supraestruturas, levando às revoluções liberais do século XVIII - a norte-americana, de 1776, a francesa, de 1789 -, que contagiaram o processo de independência das nações latino-americanas.

Benefício problemático e tardio, uma vez que o encontro do Velho com o Novo Mundo provocou o desaparecimento de milhares de povos, com suas culturas e linguagens próprias. As causas dessa hecatombe são várias, mas as perdas humanas ocasionadas pelas guerras de conquista não foram as mais importantes. Com efeito, o extermínio em massa dos ameríndios se explica, fundamentalmente, pela desarticulação de sua economia tradicional, uma vez que se sujeitaram a trabalhar, em limites extremos de exploração, pelos espanhóis e portugueses. Como escravos de fato - por vezes, até de direito - foram obrigados a deixar os seus grupos e encaminhados às minas, aos latifúndios monoculturais das plantations ou da pecuária em larga escala dos novos senhores que chegaram do mar. Nessas circunstâncias, malnutridos e obrigados a trabalhos exaustivos e perigosos, milhares de indivíduos foram dizimados por doenças trazidas pelos europeus, contra as quais não possuíam nenhuma resistência. Por exemplo, a varíola havia penetrado no México com o exército de Cortés e juntamente com as 
febres tifoides, contraídas por beber água do lago depois de cortados os aquedutos, havia minado a resistência dos defensores de Tenochtitlán. A partir de então, as enfermidades europeias reduziram os índios com espantosa rapidez. Estudos bem documentados apontam para as cifras seguintes, correspondentes à população do México: 1519 - 11.000.000; 1540 6.427.466; 1565 - 4.409.180; 1597 - 2.500.000 (PARRY, 1964, p. 319).

No tocante ao Peru, embora não disponhamos de cifras tão detalhadas, todos os autores concordam que a entrada dos espanhóis na América diminuiu radicalmente os seus habitantes originais. Em 1520, quando Francisco de Pizarro iniciou a conquista do Império Inca, a população indígena seria de cinco a nove milhões de habitantes, total auferido pelo historiador Noble David Cook (1982), após anos de trabalhos que realizou, com base na arqueologia, capacidade de adaptação dos sistemas agrícolas, mortalidade por doenças, taxas de despovoamento e projeções do senso. O declínio catastrófico da população, segundo ele, decorreu do contato com os europeus: um século após Pizarro, esse número diminuíra para seiscentos mil.

Em decorrência da conquista, em muitos lugares a agricultura comunal ficou totalmente desfeita, pois se abandonaram as antigas instalações de irrigação, fazendo com que muitas regiões, especialmente na planície costeira do Peru, voltassem a se converter em desertos. $\mathrm{O}$ descenso da população continuou durante mais de cem anos, não havendo, até bem entrado o século XVII, nenhum sinal claro de recuperação. Desse modo, a nascente sociedade europeia teve de fazer frente, nos últimos anos do século XVI, a uma carestia periódica de cereais e a uma crescente escassez de mão de obra, acarretando um aumento da pressão que se fazia sobre as terras pertencentes a povoados indígenas. Os labregos que perdiam suas terras acabavam permanecendo nelas como peões ou colonos reduzidos à semi-servidão. Por conseguinte, a agricultura em grande escala dos espanhóis contribuiu para a decadência da agricultura indígena e à generalização dos latifúndios de propriedade espanhola (PARRY, 1964, p. 319-320).

Na zona lusófona, o Brasil ajuda a compor a imagem do etnocídio que atingiu a América, com resultados que se projetam até nossa época.

As cifras apontam para quatro ou cinco milhões de indígenas, divididos em numerosos grupos, com línguas próprias e traços culturais bastante singulares, quando a esquadra cabralina desembarcou na Ilha de Vera Cruz, chamada em seguida de Terra de Santa Cruz e, por fim, de Brasil. Na linguagem jesuítica, o pau - a árvore cor de brasa - venceu a cruz, indicando uma vitória diabólica, que seria reproduzida nas crônicas sobre os pecados e vícios dos ameríndios. As imagens que se vão depositando nas narrativas de viagens apostam fortemente no exótico das culturas autóctones do Brasil, com ênfase na antropofagia e na sensualidade das mulheres. 
Estabelecia-se, portanto, o contraste entre o canibal selvagem e o branco civilizado, traço que se intensificou no século passado, através das mídias representadas pelo cinema e televisão. Os desenhos animados, por exemplo, apresentam roteiros em que um explorador europeu é capturado por uma tribo antropófaga da África ou da América, transmitindo a concepção de barbárie dos povos alógenos à Europa, inserida em uma "ideologia colonial, ou seja, num conjunto de pressupostos, nem sempre verdadeiros, que reforçam a inferioridade dos povos africanos e ameríndios" (RAMINELLI, 2017, p. 11-12).

Os totais das perdas humanas decorrentes da colonização lusitana são inseguros, porém, apresentam-se como estimativas plausíveis. No primeiro século da colonização brasileira, relatos de jesuítas e de autoridades seculares já dão conta de uma catástrofe demográfica que atingia os silvícolas, destruindo aldeias inteiras e retirando do branco a possibilidade de subsistir no ambiente tropical, considerado inóspito para a sua raça. Hoje, os milhões de índios brasileiros estão reduzidos a aproximadamente novecentos mil, uma cifra que estava ainda mais resumida antes do aumento da natalidade propiciado por políticas protetoras específicas, instaladas a partir do século passado.

Assim como aconteceu com os novos súditos de Castela, as razões do morticínio dos habitantes autóctones do Brasil repousam, fundamentalmente, na exploração radical dos indígenas, desestruturando a sua economia tradicional. Os metais e pedras preciosos, obtidos à custa do sangue ameríndio, financiaram a conquista do mundo pelos burgueses, enquanto despovoavam pueblos e aldeias inteiras. Prata e ouro que se desviaram, desde o século XVI, da Espanha para as grandes casas bancárias internacionais, sustentando o domínio europeu sobre os demais continentes. No século XVIII, o ouro e os diamantes brasileiros financiaram a Revolução Industrial da Inglaterra. Em ambos os casos, Espanha e Portugal funcionaram como plataformas do mercantilismo europeu, no contexto do qual suas possessões americanas estiveram submetidas a um duplo colonialismo: o de suas metrópoles e o referente ao capitalismo internacional.

Os Guarani contemporâneos chegaram ao litoral do Brasil em finais do século XIX, a partir do Mato Grosso do Sul, do Paraguai e da Argentina, forçados pela invasão de suas terras por colonizadores e em busca da Terra sem Mal, Yvy Mara ey, o seu paraíso mítico. Em grande parte, foram tangidos pela Guerra da Tríplice Aliança, que opôs Brasil, Argentina e Uruguai contra o Paraguai (1865-1870), exercendo um forte impacto sobre o ambiente ocupado pelos Kaiowá e Guarani, na medida em que os obrigou a abandonar as suas terras ancestrais, como proteção contra a guerra dos "brancos" (embora houvesse batalhões de índios entre os combatentes de ambos os lados). Ao término da guerra, as autoridades brasileiras produziram 
uma política de colonização do território meridional - concebido como um vazio populacional - fazendo tabula rasa dos índios que ali moravam. Em princípios do século XX, essa política criou o SPILTN (Serviço de Proteção aos Índios e Localização de Trabalhadores Nacionais), munido de postos indígenas e encarregado de incorporar os índios à massa dos trabalhadores brasileiros. Essa política visava a solidificar as fronteiras, historicamente disputadas entre Portugal e Espanha, disputa que se projetou no período pós-Independência às nações soberanas platinas, dada a importância estratégica do Rio da Prata (“a falsa porta” para o Peru), na geopolítica da região (CARIAGA, 2016, p. 80-81).

As fronteiras não demarcadas ou violadas dos indígenas brasileiros, em nome de um desenvolvimento "sustentável", não encontram nenhuma justificativa, a não ser na ação que resiste a essa marcha do capital, e que leva em conta que a vida individual só adquire significado pela participação na luta coletiva. Se partirmos da ideia de que as sociedades se caracterizam, primordialmente, pela natureza das necessidades de seus grupos e dos recursos de que dispõem para satisfazê-las, teremos que nos reportar à alteridade indígena, no âmago da colonização, para que entendamos os processos adaptativos ocorridos para encontrar soluções mais ou menos adequadas e completas entre os seus traços culturais tradicionais e as necessidades advindas do sistema capitalista hegemônico. Nesse equilíbrio, as situações de crise surgem como dificuldade ou impossibilidade de correlacionar as necessidades com a sua satisfação.

Os indígenas americanos vivem a sua identidade num cenário marcado pela diversidade étnica e por situações de autonomia e autoafirmação. No drama por eles encenado, combinamse necessidades de sobrevivência com a convicção sobre os significados positivos de seus valores ancestrais, identificando o significado da intransigência dessas populações em abrir mão de elementos culturais que lhes são próprios. Faz-se necessário salientar que, no decorrer do século $\mathrm{XX}$, o contraste entre o pensamento indígena e o acadêmico se esvaiu, e a ciência passou a se reconhecer como uma das numerosas formas de conhecimento, abrindo-se para o diálogo e criticando o poder hegemônico do saber científico diante das formas alternativas de compreensão. Uma das diferenças angulares entre o modo indígena de compreender o universo e o modo científico reside no fato de que, para o primeiro, "uma coisa só faz sentido quando é sentida", posição que põe em xeque a dicotomia clássica entre a razão e o sentimento, tão cara ao racionalismo ocidental (TASSINARI, 2016, p. 7-8).

\section{Conclusão}


A cultura ancestral indígena encontra-se em luta contra fatores externos, mas também endógenos oriundos do fascínio provocado pela potência técnica, pelos objetos, pela ciência dos brancos. O termo "desenvolvimento" apresenta-se como um desafio para os povos indígenas, conscientes que a aplicação desse slogan à sua realidade coloca graves problemas, constituindo fontes de fracassos e de desvios repetidos para a vitalidade de sua própria cultura. Mas as práticas tradicionais resistem e procuram quebrar o silêncio e os equívocos históricos que as marcaram por interpretações dos próprios indígenas, representados por lideranças ativas e conscientes dos papéis que devem exercer no cenário contemporâneo, brasileiro e internacional. Essas falas deixam claro que a cultura indígena é o terreno sobre o qual as mudanças culturais devem ser construídas. Em movimento correlato, os planejadores das sociedades "desenvolvidas" devem levar em conta os valores e as estruturas tradicionais, com os quais se encontram estreitamente ligados, esforçando-se não para destruir, como foi feito no passado, mas para preservar os fundamentos pluriculturais dos povos latino-americanos, enraizados em um passado longínquo, mas que se adaptam continuamente às mudanças do meio, configurando um processo identitário que não abdica dos valores ancestrais e reinterpreta os elementos das sociedades capitalistas à sua luz e juízo próprios. O lugar da fala tem sido cada vez mais ocupado pelos indígenas, demonstrando a preocupação dos setores progressistas da sociedade em compreender outras formas de existência, capazes de servirem de contraponto à identidade única pretendida pelo capitalismo digital. A diversidade da cultura americana, por si só, aponta para a riqueza de repertórios possíveis e de suas condições desiguais de valorização perante um sistema político marcado pela ideologia do lucro e pelo domínio de senhores sobre segmentos étnico-raciais historicamente marcados como inferiores. A questão proveniente dos embates dos ameríndios com os burgueses conquistadores significou a expropriação de seus territórios e culturas, em um processo etnocida real e simbólico plurissecular. Contra esse processo, centenas de povos indígenas organizam movimentos de resistência, defendendo patrimônios culturais próprios, baseados na circulação geracional de saberes e fazeres distantes das noções de lucro e propriedade.

\section{Referências Bibliográficas}

BARTH, F. Grupos étnicos e suas fronteiras. In: POUTIGNAT, P. Teorias da etnicidade seguido de grupos étnicos e suas fronteiras de Fredrik Barth. São Paulo: Editora da UNESP, 1998.

BRAUDEL, F. O Mediterrâneo e o Mundo Mediterrânico na época de Filipe II. São Paulo: Martins Fontes, 1983. 
CARIAGA, D E. Considerações sobre a territorialidade e as transformações entre os Kaiowá e Guarani em Te'ýikur, Caarapó-MS. In: SILVEIRA, N. H. et al. (orgs.). Diálogos com os Guarani: articulando compreensões antropológicas e indígenas. Florianópolis: Editora da UFSC, 2016.

COOK, N. D. Demographic Collapse: Indian Peru, 1520-1620. Cambridge: Cambridge Latin American Studies, 1982.

CUCHE, D. A noção de cultura nas ciências sociais. 2. ed., Bauru: EDUSC, 2002.

CUNHA, M. C. Índios no Brasil: história, direitos e cidadania. São Paulo: Claro Enigma, 2012.

DESCOLA, P. Outras naturezas, outras culturas. Trad. Cecília Ciscato. São Paulo: Editora 34, 2016.

DONGHI, T. H. Historia Contemporanea de America Latina. 3. ed. El libro de Bolsillo. Madrid: Alianza Editorial, 1972.

GRUZINSKI, S. As quatro partes do mundo: história de uma mundialização. São Paulo: Edusp, 2014.

HALL, S. A identidade cultural na pós-modernidade. Rio de Janeiro: DP\&A, 1992.

HOLANDA, Sérgio Buarque de. Caminhos e fronteiras. Rio de Janeiro: José Olympio, 1957.

MONIOT, H. L' histoire des peuples sans histoire. In: LE GOFF, J.; NORA, P. Faire de l'histoire: nouveaux problèmes. Paris: Gallimard, 1974.

POUTIGNAT, P.; STREIFF-FENART J. Teorias da etnicidade seguido de grupos étnicos e suas fronteiras de Fredrik Barth. São Paulo: Editora UNESP, 1998.

RAMINELLI, R. Prefácio. In: CHICANGANA-BAYONA, Y. A. Imagens de canibais e selvagens do novo mundo do maravilhoso medieval ao exótico colonial (séculos XV-XVII). São Paulo: Editora Unicamp, 2017.

TASSINARI, A. Apresentação. In: SILVEIRA, N. H; MELO, C. R.; JESUS, S. C. Diálogos com os Guarani: articulando compreensões antropológicas e indígenas. Florianópolis: Editora da UFSC, 2016.

VEYNE, P. Como se escreve a História. Trad. António José da Silva Moreira. Lisboa: Edições $70,1983$. 